\section{O museu dos povos indígenas do oiapoque - kuahí Gestão do Patrimônio Cultural pelos Povos Indígenas do Oiapoque, Amapá.}

\author{
Lux Vidal ${ }^{2}$
}

\section{Introdução}

As artes indígenas possuem sua fonte de inspiração em uma tradição milenar e representam, na maioria das vezes, a filosofia de um povo, os seus valores, gostos, práticas sociais e religiosas. Possuem, ainda, uma relação forte com o meio ambiente, com a terra em que vivem, que conhecem, dominam e, na medida do possível, preservam.

Conseqüentemente, as manifestações artísticas destes povos também têm história, os artistas possuem histórias de vida e especialmente possuem nome e personalidade própria, algo apenas recentemente reconhecido. Deste modo, a arte tradicional, assim como as interessantes e criativas inovações não têm sido, ao longo dos tempos, apreciadas em termos justos, sendo consideradas apenas "artesanato indígena", ignorando-se a qualidade e continuidade histórica destas manifestações que vão se renovando com o tempo. Por outro lado, nas últimas décadas, tem-se observado esforços tanto por parte dos índios, que hoje estão mais bem informados e também viajam mais, como por parte de antropólogos, artistas, curadores de museus ou bienais, em valorizar as artes indígenas a partir de novas atitudes estéticas e participativas.

1 Trabalho apresentado na Mesa 5: Museus, identidades e patrimônio cultural.

2 Antropóloga. Professora do Programa de Pós-Graduação em Antropologia. Universidade de São Paulo.
Atualmente, temos observado a proliferação de museus indígenas e regionais em todo o mundo, modelo que vem sendo valorizado por possuir características próprias, diversas do modelo de museu conhecido pelas grandes cidades. Neste contexto é que se insere o Museu Kuahí dos Povos Indígenas do Oiapoque, tema deste artigo.

\section{O Contexto}

Para melhor entender a especificidade do Museu Kuahî é preciso oferecer algumas informações preliminares sobre a região.

Os povos indígenas do extremo norte do Amapá, habitantes da bacia do rio Uaçá e baixo curso do rio Oiapoque - Karipuna, Palikur, Galibi Marworno e Galibi Kali'na - são o resultado de várias migrações e fusões antigas e mais recentes de etnias diferentes e mesmo nãoíndios. São portadores de tradições culturais heterogêneas, histórias de contato e trajetórias diferenciadas, assim como suas línguas e religiões. Mesmo assim esses povos têm conseguido conviver e construir, ao longo do tempo, um espaço de interlocução, especialmente hoje pelo viés das Assembléias anuais, que reúnem as quatro etnias, e de suas organizações indígenas.

Mesmo assim, apesar das diferenças, prevalece uma visível solidariedade entre esses povos por compartilhar um mesmo território, vivenciar uma situação geopolítica comum, por manter e reativar relações de parentesco e ajuda mútua, assim como lutar unidos pela terra, saúde,

3 Kuahí - pronuncia-se "kuarî" - é o nome dado ao Museu pelos índios. É um pequeno peixe da região e o nome de um padrão gráfico muito utilizado na decoração de objetos. 
educação e infraestrutura. Compartilham uma cosmologia específica, indígena, Carib, Aruak, Tupi e também cristã, um aspecto marcante que os índios definem como "nosso sistema"

Boa parte da população indígena do baixo Oiapoque se comunica em vários idiomas, português e patoá ou kheoul (língua franca regional), idioma nativo dos Karipuna e Galibi Marworno; os Palikur e Galibi Kali'na falam suas respectivas línguas nas aldeias. Alguns índios também sabem se comunicar em francês.

A paisagem típica da região habitada pelos povos indígenas do Oiapoque é de savana alagada, banhada por três grandes rios, o Uaçá, o Urucauá e o Curipi, além de inúmeros afluentes, igarapés e lagos. $\mathrm{O}$ rio Oiapoque delimita a fronteira entre o Brasil e a Guiana Francesa. A oeste da terra indígena, uma rica cobertura de floresta tropical, com muitas palmeiras, vai ao encontro das montanhas do Tumucumaque; a leste, o rio Cassiporé, o Cabo Orange e o Oceano Atlântico. As aldeias e as roças ocupam diferentes ilhas. É uma região repleta de aves.

Esse território é, antes de tudo, um espaço vivido. Os índios possuem um conhecimento refinado desta vasta região, tão rica e diversificada. Toda esta paisagem, segundo os índios, é habitada por seres humanos, animais e vegetais e também por seres "do outro mundo", que se manifestam pela intermediação dos pajés. Um mundo predominantemente aquático, cuja cosmologia privilegia os seres sobrenaturais que habitam "o centro da mata e o fundo das águas" Região que antigos cartógrafos denominavam o “pays sous l'eau", peí abã dji lo em patoá.

\section{A idéia de um museu}

Em 1997, após uma viagem a Alemanha, França e Portugal de algumas lideranças indígenas, em companhia da deputada Janete Capiberibe, os povos indígenas da região propuseram a criação de um museu em Oiapoque, no centro da cidade, para dar visibilidade à cultura indígena $\mathrm{e}$, ao mesmo tempo, ser um centro de referência, de memória, de documentação e de pesquisa para os índios e a sociedade oiapoquense. Esta proposta surgiu da vontade dos índios de participar, cada vez mais, em pé de igualdade - ainda que de modo diferenciado - da vida regional e nacional. Cientes de sua riqueza cultural e material, das possibilidades de produção e divulgação etnocientífica, artesanal e artística; cientes também das possibilidades de desenvolvimento sustentável e da urgência na melhoria dos programas escolares, os Povos Indígenas do Oiapoque se propuseram a defender o Museu Kuahí como espaço adequado para incentivar um vasto conjunto de atividades, pesquisas e ações que beneficiariam como um todo as comunidades indígenas e suas iniciativas.

Ao mesmo tempo, o Museu possibilitaria o estreitamento de relações entre os índios e a população do município de Oiapoque. A proximidade com as aldeias, por sua vez, viria a inseri-lo no contexto de origem, facilitando a compreensão de seu acervo, estando distante o suficiente das mesmas para permitir às comunidades uma separação de seu cotidiano, conduzindo os índios a uma visão mais crítica de si próprios e de seu patrimônio cultural. Além disso, possibilitaria o intercâmbio com povos indígenas e museus de todo o Brasil e do mundo, através de convênios com instituições e universidades.

Outro objetivo do Museu seria o de possibilitar alternativas de renda por meio da comercialização planejada da produção artesanal. O Museu viria a dar dignidade e visibilidade aos artefatos produzidos nas aldeias e, sobretudo, aos mestres artesãos e artistas, além de suscitar a preocupação com a sustentabilidade da matériaprima utilizada.

Vários índios da região conheciam o Museu Paraense Emilio Goeldi, em Belém, e haviam visto fotografias do Museu Magüta dos índios Ticuna, do rio Solimões. Eles foram fonte de inspiração para a elaboração da proposta de construção do Museu Kuahí.

A proposta concreta para a construção do Museu foi apresentada pelas lideranças indígenas ao governo do Amapá em 1998 e incluída formalmente no Programa de Desenvolvimento Sustentável do então governador João Alberto Capiberibe. 
Em 2000 foi iniciada a construção do Museu e os índios, assessorados por mim e por Lucia H. van Velthem, do Museu Paraense Emilio Goeldi, entregaram ao governo um conjunto de documentos: justificativa e objetivos do Museu, Estatuto, lista de equipamentos etc. Tratavase de uma proposta inovadora, por não fazer deste um museu sobre os índios, mas dos índios.

Segundo planejado o Museu seria mantido pelo estado do Amapá e gerido pelos próprios índios, diretamente envolvidos em todas as atividades e com representação majoritária no Conselho Curador. Cursos e oficinas de capacitação seriam oferecidos para a formação dos técnicos em museologia, pessoas escolhidas pelas próprias comunidades indígenas. Esperavase por parte do governo um apoio efetivo aos povos indígenas e suas manifestações culturais, de cunho não-paternalista, assumindo que a construção da cidadania para os índios se fundamenta nos seus próprios valores, dinâmica e processo histórico.

\section{A implantação do Museu}

O Museu Kuahí dos Povos Indígenas do Oiapoque é uma entidade pública, sem fins lucrativos, de administração indireta vinculada à estrutura organizacional da Secretaria de Estado da Cultura do Amapá. O Museu tem por finalidade dar visibilidade à diversidade sóciocultural dos povos indígenas do Oiapoque das etnias Galibi Kali'na, Galibi Marworno, Karipuna e Palikur e promover a igualdade cultural entre a população do município de Oiapoque.

Embora o Museu Kuahí tenha sido inaugurado em 2007, sua presença já vem se fazendo sentir há alguns anos, quando foram ministrados os primeiros cursos de capacitação museológica para uma turma de quinze indígenas escolhidos pelas próprias comunidades de acordo com a formação escolar e interesse de cada participante. Estes cursos foram ministrados em Oiapoque, no Museu Paraense Emilio Goeldi e no Museu de Arte de Belém. Nesta cidade foram também visitados o Museu de Estado, o Museu de Arte Sacra, galerias de arte e localidades da própria cidade de interesse histórico e turístico.

Paralelamente, os resultados de variadas pesquisas antropológicas (vide bibliografia) e especialmente dois projetos culturais desenvolvidos nas aldeias foram de significativa importância para estimular a retomada cultural que estas etnias têm presenciado. Trata-se dos projetos: 1) de Resgate e Fortalecimento Cultural, desenvolvido pela Associação dos Povos Indígenas do Oiapoque - APIO, em parceria com o Programa Demonstrativo para Populações Indígenas do Ministério do Meio Ambiente - PDPI / MMA; e 2) de Formação de Gestores do Patrimônio Cultural, desenvolvido junto aos professores indígenas que atuam nas aldeias da BR - 156, realizado pelo Iepé - Instituto de Pesquisa e Formação em Educação Indígena, em parceria com a Petrobrás Cultural.

O Projeto de Resgate e Fortalecimento Cultural - APIO / PDPI, elaborado com os índios, visou incentivar os velhos artesãos e artesãs a transmitir seus conhecimentos, saberes e técnicas relativos às mais diversas manifestações artísticas, artesanais, materiais e imateriais, às gerações mais jovens. A proposta foi a de garantir a transmissão de conhecimentos em risco de extinção, uma vez que seus últimos detentores somam número bastante reduzido, a maioria já em idade avançada.

A Formação de Gestores do Patrimônio Cultural - Projeto Iepé / Petrobrás Cultural, por sua vez, teve o objetivo de formar professores indígenas para atuar como gestores de seu patrimônio cultural material e imaterial, através do aprendizado de procedimentos de seleção, preservação, pesquisa, registro e divulgação interna e externa dos bens culturais. Embora este seja um processo lento e de resultados difusos, assume grande importância a médio e longo prazo. As aldeias localizadas ao longo da BR-156 foram escolhidas para a realização deste projeto em função da situação de grande vulnerabilidade em que se encontram, ocasionada pelas obras de pavimentação da estrada e da passagem da linha de transmissão de energia, mencionadas anteriormente.

Caminhando em concomitância com estes projetos, o Museu Kuahí desempenha pa- 
pel de suma importância, ao possibilitar a mudança da percepção indígena sobre a própria produção, nele exposta em suportes, vitrines ou armazenada na reserva técnica. De objetos de uso, comercializáveis ou descartáveis, as peças transformam-se em objetos-documento, com outra identidade e significado. Este novo posicionamento da produção cultural permite um olhar diferente, distanciado e crítico sobre a mesma. Ao mesmo tempo, torna a gestão da produção cultural mais interessante e integrada ao mundo moderno.

\section{Da inauguração aos dias de hoje}

O Museu Kuahí foi inaugurado no dia 19 de abril de 2007 - Dia Nacional do Índio com a presença de indígenas, autoridades governamentais como o governador do estado Antonio Waldez Góes da Silva e de representantes da Secretaria do Estado de Cultura do Amapá - Secult/AP, além da população local.

A inauguração do Museu, com uma significativa exposição inaugural, ocupando todos os ambientes, não teria sido possível sem o convênio 158/2005 entre a Secult/AP e o Ministério da Cultura - MinC. Foi graças a esse convênio que a Secult/AP pôde mobiliar e equipar as diversas instalações. O Museu dispõe hoje de luminosas salas de exposição, reserva técnica, auditório equipado e apropriado para amplo público, sala de processamento documental, biblioteca, sala de leitura, sala de pesquisa e sala pedagógica. Na entrada, um grande hall acolhe os visitantes e abriga ainda a loja para venda de artesanato. Há também espaços externos como uma grande varanda, também bastante freqüentada. Tem, enfim, à disposição de todos os indígenas e cidadãos de Oiapoque uma exposição de artefatos indígenas, uma coleção bastante representativa com tendência a aumentar com novas contribuições. Os livros e revistas da biblioteca vêm sendo cada vez mais solicitados pelos alunos e professores para ajudá-los em seus próprios cursos de formação.
E por falar em cursos de formação, o convênio Secult/MinC possibilitou a retomada de um extenso e intenso processo de formação profissional, técnica, museológica e museográfica, aos dezenove indígenas que trabalham no Museu, sendo que quinze, dentre eles, recebem bolsas de estudo diretamente subsidiadas pelo convênio. Nesse período de formação, caracterizamos o Museu Kuahí como um museu-escola. Nessa direção, de abril de 2007 até a data presente, em quase um ano de funcionamento, foi realizado um esforço no sentido de organizar a equipe de bolsistas junto aos setores a que foram destinados desde sua seleção, realizada no curso de capacitação museológica e antropológica ministrado em 2006. Destaco aqui a contribuição do antropólogo Francisco S. Paes, assessor do Museu Kuahí desde sua inauguração.

Em 2007 foram realizados junto aos técnicos indígenas do Museu os cursos de capacitação em Conservação Preventiva, História da América Indígena e do Amapá e Administração e Gestão. Para 2008 estão previstos os módulos de capacitação em Antropologia (dois módulos), Arqueologia, Jornalismo Comunitário e Editoração de Boletim, Leitura e Produção Textual, Linguagem Audiovisual, Museologia, Documentação, Ação Educativa e Métodos de Pesquisa.

Novas ações e projetos que permitem a ampliação dos trabalhos junto às comunidades indígenas e não-indígenas da região do Oiapoque estão em curso: a realização de exposição temporária e evento de encerramento do Projeto APIO/PDPI de Valorização e Resgate Cultural; a construção de uma proposta de exposição temporária sobre a arte dos índios Galibi Kali'na da Guiana Francesa; exposição temporária sobre os resultados do projeto Iepé/Petrobrás Cultural; Seminários sobre meio ambiente em parceria com as ONGs The Nature Conservancy (TNC), Iepé e a APIO; mostras de vídeo e palestras abertas ao público em geral, assim como nas escolas indígenas, realização de Turés, assembléias e outras atividades relevantes para os índios e para a sociedade oiapoquense.

O Museu tem sido bastante freqüentado e elogiado por parte dos visitantes indígenas, da cidade de Oiapoque e de todo o Amapá, além dos inúmeros turistas, especialmente guianenses e franceses. 
Cabe ressaltar que os processos e projetos do Museu, assim como seu Estatuto (ainda não reconhecido pela Secult/AP) seguem, na medida do possível, as diretrizes da Comissão Internacional de Museus - ICOM - e contam com a assessoria de profissionais experientes nas áreas de antropologia, museologia, arqueologia, ação educativa e outras.

\section{Considerações acerca das coleções sobre os Povos Indígenas do Oiapoque}

Um aspecto interessante das atividades de resgate cultural nas aldeias, da inauguração do Museu Kuahí, assim como da encomenda de 250 artefatos para a exposição "A Presença do Invisível - vida cotidiana e ritual entre os Povos Indígenas do Oiapoque" montada em 2007 no Museu do Índio - RJ, é a formação de várias coleções, em diferentes momentos e que comparadas entre si, revelam muito sobre a própria história dos Povos Indígenas do Oiapoque, o papel dos museus e da documentação, a pesquisa antropológica e as ações efetivas de valorização e fortalecimento cultural. Cada coleção em si é relevante no conjunto das coleções, quando as características e o valor de cada uma se revela com relação às outras. $\mathrm{O}$ trabalho de curadoria para a exposição do Rio de Janeiro, assim como o seminário sobre Identidades e Patrimônio Cultural, organizado pelo MAE (Museu de Arqueologia e Etnologia da USP) em junho de 2007, deixou este aspecto bem claro.

Existe no Museu do Índio do Rio de Janeiro uma coleção antiga, dos anos 1940-50 sobre os Povos Indígenas do Oiapoque, essencialmente sobre os Palikur. São objetos valiosos recolhidos por Eurico Fernandes, antigo funcionário do SPI na região e outros indigenistas. A documentação é deficiente e a descrição sumária. Há peças de plumária que hoje não produzem mais, ou fazem com decoração diferente. Antigos clarinetes, os famosos turé, e pequenos objetos delicados, que serviam como convites para os rituais, além de pequenas bordunas que as mulheres usavam durante os rituais para chamar a chuva compõem a coleção. Estes objetos compõem a exposição "A Presença do Invisível” ao lado das peças contemporâneas.

Os índios, convidados à inauguração da exposição, em junho de 2007, ficaram admirados e muito satisfeitos de (re)ver estes artefatos mais antigos e bem conservados. O Museu do Índio também possui uma coleção de armas de pesca; estas, até hoje não mudaram, são os mesmos artefatos confeccionados com madeira, taboca, fio de curuá e ferro batido. Em 2008, como em 194050 , as mesmas formas, o mesmo uso cotidiano. Por outro lado, comparando os típicos chapéus Palikur, se antigamente o cobre-nuca de plaquetas de buriti era sempre ornamentado com marcas geométricas, hoje os índios pintam desenhos mais figurativos com temas míticos ou da vida cotidiana, ou ainda capas de revistas ou DVDs.

Sabemos que há uma coleção Palikur na Europa, mas não a consultamos. São peças recolhidas por Curt Nimuendajú em 1926, quando pesquisou na região. Estão documentadas graças à monografia deste antropólogo. Há também uma pequena coleção no Museu Paraense Emilio Goeldi, pouco expressiva e pouco documentada, mas com algumas cerâmicas Galibi-Kali'na, artesania que não mais realizam, trazidas pelo antropólogo Expedito Arnaud na década de 1960. Os índios reconheceram que as peças tinham sido elaboradas pela mãe do velho chefe atual, assim como algumas vestimentas.

A primeira coleção mais sistemática e documentada, doada ao MAE USP foi aquela realizada por mim e Artionka Capiberibe, entre os Palikur, Karipuna e Galibi-Marworno na década de 1990. Os índios faziam poucos artefatos para a venda, principalmente colares, mas usavam cuias decoradas, faziam cestaria, especialmente para o tratamento da mandioca, assim como raladores e esculturas para as festas do Turé - mastros e bancos -, além de instrumentos musicais.

Esta coleção de 260 peças não foi pensada a priori, mas acompanha as pesquisas de campo que se iniciaram em 1990 na região, por parte de pesquisadores da USP. Há uma boa representação de todas as categorias artesanais, peças bem documentadas, mas do ponto de vista estético deixa a desejar. Ainda não havia sido 
iniciado o projeto de resgate cultural e nem toda a pesquisa sobre as marcas nos mais diferentes suportes. Sendo assim, ela é um marco histórico, a primeira coleção que acompanha o início das pesquisas entre os Povos Indígenas do Oiapoque, segundo um viés teórico que valoriza a história, os processos e reconhece a heterogeneidade das manifestações culturais na região. Esta coleção se insere entre uma mais antiga, a do Museu do Índio e as duas coleções seguintes, já frutos dos projetos de valorização cultural nas aldeias, das pesquisas sobre cosmologia, xamanismo, cultura imaterial e patrimônio cultural indígena, com a formação de pesquisadores indígenas, assim como da construção do Museu Kuahí.

A coleção do Museu é formada por mais de 300 peças, encomendadas, representando todos os artefatos mais expressivos de uso cotidiano e ritual e também peças fabricadas para o comércio.

Em suma, tanto para o acervo do Museu Kuahí como para a exposição "A Presença do Invisível" no Museu do Índio, foram produzidas duas grandes coleções de artefatos etnográficos de altíssima qualidade, fato que surpreendeu a todos, inclusive aos próprios índios. Quando as coleções recolhidas nas aldeias dos diferentes rios chegaram ao Museu Kuahí e foram armazenadas em duas salas, a espera de seu destino, o conjunto causou impacto. Alguns índios disseram que nunca haviam visto certos artefatos, não os conheciam. Outros não se cansavam de perguntar e tirar fotos. De fato, não sabiam que tudo isso ainda existia e poderia ter algum valor em outros contextos. Os artefatos recolhidos sob forma de coleção representaram algo novo para eles. Especialmente a coleção para a exposição do Rio, acompanhada de documentação, fotografias, vídeos, site, design museográfico apurado e participação dos índios foi um evento muito importante para dar visibilidade aos Povos Indígenas do Baixo Oiapoque, realçando sua identidade diferenciada. O Museu Kuahí e especialmente as atividades e conhecimentos a ele ligadas ganharam sentido em um contexto cultural mais amplo.

Há ainda uma outra pequena coleção, resultado do projeto de Resgate Cultural APIO / PDPI - MMA. Enquanto os velhos repassavam seus conhecimentos aos mais jovens, os artefa- tos produzidos eram levados à sede da APIO e guardados em uma sala. São peças valiosas, muitas delas experimentais e testemunhas de todo um esforço de transmissão de saberes entre gerações. Fazem parte do acervo peças bem antigas que não eram mais fabricadas, mas também inovações, tanto na forma como na decoração. Esta coleção foi, em 2007, incluída no acervo do Museu Kuahí, mas como coleção específica e separada, testemunha deste trabalho de resgate.

$$
* * *
$$

Um outro aspecto interessante com relação ao Museu é que a demora em implementálo fez com que os índios se apropriassem dele, inclusive pedindo insistentemente ao governo que o inaugurasse. $\mathrm{O}$ Museu lhes aparece, assim, como mais uma conquista do movimento indígena. Como conseqüência deste processo, o Kuahí hoje é considerado como mais uma instituição indígena na região, tal como as outras associações indígenas ou a FUNAI (também comandada pelos índios), isto é, um sujeito político no contexto institucional indígena da região, com poder de representação. Por outro lado, muitos eventos da cidade de Oiapoque acontecem no Museu, pelo espaço de qualidade que ele oferece, o que também prestigia os índios no meio urbano e municipal.

Uma última questão a ser considerada diz respeito à documentação. Há uma discussão com os índios sobre os documentos que devem compor os arquivos confidenciais, apenas acessíveis aos indígenas sob a orientação do Conselho de Apoio Indígena ao Museu Kuahí, e o que é acessível ao público. Isto é, o Museu levanta uma série de discussões muito atuais, sobre propriedade intelectual e maneiras de documentar e divulgar a cultura indígena, não de maneira abstrata, mas bem concreta.

\section{Bibliografia:}

CASTRO, Esther de. "O Museu dos Povos Indígenas do Oiapoque: um lugar de produção, conservação e divulgação da cultura" In: Aracy Lopes da Silva $e$ 
Mariana Ferreira (orgs). Práticas Pedagógicas na Escola Indígena. São Paulo: Global Editora, 2001.

GALLOIS, Dominique T. (org). Patrimônio Cultural Imaterial e Povos Indígenas. São Paulo: Iepé, 2006.

NIMUENDAJÚ, Curt. Os índios Palikur e seus vizinhos. Manuscrito traduzido por Tekla Hartmann do original "Die Palikur Indianer und ihre Nachbarn". NHII/USP, mimeo, 1926.

PAES, Francisco S. Curipi. Vídeo de $27 \mathrm{~min}$. São Paulo: Laboratório de Imagem e Som em Antropologia - LISA / FFLCH - USP, 2001.

TASSINARI, Antonella M. I. No Bom da Festa: o processo de construção cultural das famílias Karipuna do Amapá. São Paulo: Edusp, 2003.

VIDAL, Lux B. "O modelo e a marca, ou o estilo dos 'misturados': cosmologia, história e estética entre os Povos Indígenas do Uaçá". Revista de Antropologia, $42(1 / 2), 1999$.

VIDAL, Lux B. "O ralador de mandioca: Povos Indígenas do Uaçá, Oiapoque, Estado do Amapá". In: Joaquim Pais de Brito (coord.). Os Índios, Nós. Lisboa: Museu Nacional de Etnologia, 2000b.

VIDAL, Lux B. A Cobra Grande: uma introdução à cosmologia dos Povos Indígenas do Uaçá e Baixo Oiapoque - Amapá. Publicação avulsa $\pi^{\circ} 1$. Rio de Janeiro: Museu do Índio, 2007.

VIDAL, Lux B. Povos Indígenas do Baixo Oiapoque - o encontro das águas, o encruzo dos saberes e a arte de viver. São Paulo/Rio de Janeiro: Iepé/Museu do Índio, 2007b. 